\title{
Engaging Social Media Users with Health Education and Physical Activity Promotion
}

\author{
Elia GABARRON ${ }^{\mathrm{a}, 1}$, Dillys LARBI ${ }^{\mathrm{a}}$, Eirik ÅRSAND ${ }^{\mathrm{a}, \mathrm{b}}$ and Rolf WYNN ${ }^{\mathrm{c}}$ \\ ${ }^{a}$ Norwegian Centre for E-health Research, University Hospital North Norway, Tromsø, \\ Norway \\ ${ }^{\mathrm{b}}$ Department of Computer Science, UiT The Arctic University of Norway, Tromsø, \\ Norway \\ ${ }^{c}$ Department of Clinical Medicine, UiT The Arctic University of Norway, Tromsø, \\ Norway
}

\begin{abstract}
Health-dedicated groups on social media provide different contents and social support to their peers. Our objective is to analyze users' engagement with health education and physical activity promotion posts according to the expressed social support and social media. All health education and physical activity promotion posts on Facebook, Twitter, and Instagram during 2017-2019 by a diabetes association were extracted. We identified the type of social support within these posts; and analysed the users' engagement with these posts according to the type of social support and social media channel. A total of 260 posts dealing with health education $(\mathrm{n}=200)$ and physical activity promotion $(\mathrm{n}=60)$ were published. Posts promoting physical activity received $54 \%$ more likes than posts on health education $(\mathrm{p}<0.05)$, but they were $69 \%$ less likely to receive comments and be shared (both $\mathrm{p}<0.01$ ). Posts expressing tangible assistance received 6 times more likes $(\mathrm{p}<0.001)$, and the ones indicating network support almost 11 times more shares $(p<0.05)$. Posts expressing two or more types of social support were the most engaging ( 3 times more likes, 2 times more comments, and over 6 times more shares, all $\mathrm{p}<0.001)$. Health-dedicated social media groups can be effective channels for providing health education and for promoting physical activity among individuals with diabetes. Our findings suggest that engagement with health education and physical activity promotion posts can be increased by providing tangible assistance, network support, or expressing two or more types of social support; and by posting on Facebook and Instagram.
\end{abstract}

Keywords. Diabetes; Health education; Physical activity promotion; Social media; Social support

\section{Introduction}

Health education and physical activity promotion are critical for individuals with diabetes and prediabetes for reducing the development of complications [1],[2]. Hence, diabetes social media groups can be regarded as effective educational channels for providing health education and for promoting physical activity.

${ }^{1}$ Corresponding Author: Elia Gabarron, Norwegian Centre for E-health Research, University Hospital of North Norway, Sykehusveien. 239019 Tromsø, Norway; E-mail: elia.gabarron@ehealthresearch.no. 
Participation and engagement in diabetes social media groups are linked to positive effects for their users [3]. These groups share different types of health-related contents [4], [5], and they also provide social support to their peers. Social networks and social support are known to affect patients' self-care and improve health outcomes [6]. Social support and a sense of community have been found to be central components of online support of people with different health challenges [7],[8]. In addition, social support has been found to be a predictor of physical activity in people with type 2 diabetes [9].

Social media groups can provide their users with five types of support-intended communication behaviours [10]: information support (providing information or advice); esteem support (communicating respect and confidence in abilities); network support (communicating belonging to a group of persons with similar concerns or experiences); emotional support (communicating love, concern, or empathy), and tangible assistance (providing, or offering to provide, goods and/or services).

Previous studies analyzing the expressed social support in online groups related to different health conditions have reported a higher frequency of posts expressing informational support and emotional support; tangible assistance is typically the least frequently expressed type of support [11], [12], [13], [14].

Not much is known about the types of social support that are provided in diabetes social media groups relating to health education or physical activity promotion, or how the users' engagement with these posts varies according to type of social media or type of social support.

The objective is to analyze user engagement with health education and physical activity promotion contents posted on three diabetes social media channels (Facebook, Twitter, and Instagram) according to the different types of social support.

\section{Methods}

We collected all social media posts dealing with health education and physical activity promotion published by the Norwegian Diabetes Association on their social media channels (Facebook, Twitter, and Instagram) during a 3-year period (2017-2019).

Each of the extracted posts was classified according to its main contents into "health education" or "physical activity promotion". The inter-rater agreement was found to be substantial, further details are published elsewhere ${ }^{15}$. Two independent reviewers with a background in psychology (EG, RW) read the posts and coded them according to their type of social support, following the Social Support Behaviour Code $^{10}$.

We performed negative binomial regression to assess the effect of the expressed social support and social media channel on users' engagement. The largest category in each group was used as the reference group: for the contents' topic (ref: health education); provided social support (ref: single type of social support); social support type (ref: information support); social media (ref: Twitter). Regression analyses were performed with SPSS (version 25; IBM Corp).

The Ethics Committee 2017/764/REK Sør-ØstC considered this study as falling outside the Norwegian Health Research Act. The Data Protection Officer at the University Hospital of North Norway approved the treatment of personal information in this study (ref. 0720). 


\section{Results}

A total of 260 posts published during the period 2017-2019 dealt with health education $(n=200)$ and physical activity promotion $(n=60)$. Regarding social support: a total of 214 posts expressed a single type of social support; and 46 posts were found to express two or more types of social support. The most common social support type was information support (expressed in 232 posts; 89.2\%), followed by tangible assistance (46/260; 17.7\%); network support (20/260; 7.7\%); and esteem support (13/260; 5\%). None of the posts were identified as expressing emotional support. These posts were published on Twitter (121/260; 46.5\%); Facebook (109/260; 41.9\%); and Instagram $(30 / 260 ; 11.5 \%)$. The effects of social support and social media channel on users' engagement are shown in Table 1.

Table 1. Negative binomial regression: Effects of types of social support and social media on users' engagement

\begin{tabular}{|c|c|c|c|}
\hline Independent variables & $\begin{array}{c}\text { Likes } \\
\text { OR }(95 \% \mathrm{CI})\end{array}$ & $\begin{array}{r}\text { Comments } \\
\text { OR }(95 \% \mathrm{CI})\end{array}$ & $\begin{array}{c}\text { Shares } \\
\text { OR }(95 \% \mathrm{CI})\end{array}$ \\
\hline $\begin{array}{r}\text { Contents topic } \\
\text { Health education } \\
\text { Physical activity promotion }\end{array}$ & $\begin{array}{c}{[\mathrm{REF}]} \\
1.54(1.16-2.06)^{* *}\end{array}$ & $\begin{array}{c}{[\mathrm{REF}]} \\
0.31(0.22-0.44)^{*}\end{array}$ & $\begin{array}{c}{[\mathrm{REF}]} \\
0.31(0.21-0.44)^{*}\end{array}$ \\
\hline $\begin{array}{r}\text { Provided social support } \\
\text { Single social support } \\
>2 \text { types of social support }\end{array}$ & $\begin{array}{c}{[\mathrm{REF}]} \\
3.30(2.40-4.54)^{*}\end{array}$ & $\begin{array}{c}{[\mathrm{REF}]} \\
2.34(1.66-3.29)^{*}\end{array}$ & $\begin{array}{c}{[\mathrm{REF}]} \\
6.63(4.43-9.90) *\end{array}$ \\
\hline $\begin{array}{r}\text { Type of social support } \\
\text { Information } \\
\text { Tangible assistance } \\
\text { Network } \\
\text { Esteem }\end{array}$ & $\begin{array}{c}{[\mathrm{REF}]} \\
6.51(3.76-11.27)^{*} \\
2.91(0.40-20.86) \\
1.38(0.44-4.37)\end{array}$ & $\begin{array}{c}{[\mathrm{REF}]} \\
0.71(0.41-1.23) \\
0.91(0.10-8.19) \\
0.46(0.11-1.84)\end{array}$ & $\begin{array}{c}{[\mathrm{REF}]} \\
0.66(0.37-1.19) \\
10.79(1.5-77.39)^{* *} \\
0.29(0.06-1.33)\end{array}$ \\
\hline $\begin{array}{r}\text { Social media } \\
\text { Twitter } \\
\text { Facebook } \\
\text { Instagram }\end{array}$ & $\begin{array}{c}{[\mathrm{REF}]} \\
27.98(21.36-36.64)^{*} \\
55.38(36.86-83.21)^{*}\end{array}$ & $\begin{array}{c}{[\mathrm{REF}]} \\
59.19(36.89-94.97)^{*} \\
5.65(2.95-10.82)^{*}\end{array}$ & $\begin{array}{c}{[\mathrm{REF}]} \\
12.33(9.39-16.18)^{*} \\
\mathrm{NA}\end{array}$ \\
\hline
\end{tabular}

Posts promoting physical activity received $54 \%$ more likes than posts on health education $(\mathrm{p}<0.05)$, but they were also $69 \%$ less likely to receive comments and be shared (both $\mathrm{p}<0.001$ ).

With regards to the provided social support, posts that expressed two or more types of social support had 3 times increased chances of receiving likes, 2 times increased chances of being commented on, and over 6 times increased chances of being shared (all $\mathrm{p}<0.001$ ). Posts that expressed tangible assistance were 6 times more likely to receive likes $(\mathrm{p}<0.001)$, and those that expressed network support were almost 11 times more likely to be shared $(\mathrm{p}<0.05)$.

Health education and physical activity promotion posts on Facebook and Instagram were significantly more engaging than the ones posted on Twitter. On Facebook, posts had almost 28 times increased chances of receiving likes, almost 60 
times more comments, and 12 times increased chances of being shared (all $\mathrm{p}<0.001$ ). The posts on Instagram received 55 times more likes and were 5 times more likely to receive comments (both $\mathrm{p}<0.001$ ).

\section{Discussion}

It is important to know how to engage social media users in order to improve communication, especially when attempting to communicate important information regarding health and illness ${ }^{1,16}$. In this study, we have examined how social media are used by a patient organization aiming to educate and support people with diabetes. Previous studies have shown that social support helps people deal with illness ${ }^{9,11-14}$. In our study, we have found that social media posts that express different types of social support are particularly engaging to users. Posts that engage the most are the ones that express two or more types of social support (3 times more likes, 2 times more comments, and over 6 times more shares).

In this study, information support was the most common type of expressed social support on diabetes social media groups (present in $89 \%$ of posts). Our findings are consistent with previous studies that analyzed the social support in different health dedicated groups ${ }^{11-14}$. Despite information support being the most popular expressed type of social support, posts communicating tangible assistance and network support were the most engaging ones (6 times increased chances of receiving likes, and almost 11 times increased chances of being shared, respectively).

Very few posts dealt with both health education and physical activity promotion (barely 7 posts per month over 3 years). Almost half of these posts were published on Twitter, although the ones that were published on Facebook and Instagram were more engaging. There is room to increase the number of social media posts dedicated to diabetes health education and physical activity promotion, given the known positive effect these have on this group. Educational posts could also make use of emojis, pictures, and videos, which have also been shown to have an effect on users' engagement ${ }^{15}$.

Limitations: We only collected data from a 3-year span from a national diabetes association whose social media channels are open, but only administrators can post. Our findings may not be generalizable to other diabetes social media groups or to other disease areas. Further studies could analyze the potential impact of using different types of social support in posts on different social media channels on users' health literacy and physical activity behavior.

\section{Conclusions}

Social media can be regarded as effective educational channels for providing health education and for promoting physical activity among individuals with diabetes. Our findings suggest that engagement can be increased by expressing two or more types of social support within the posts, by providing tangible assistance (i.e., providing goods or services that could be useful for people with diabetes), network 
support (i.e., communicating belonging to the diabetes group), and by posting on Facebook and Instagram.

\section{Acknowledgments}

We sincerely thank the Norwegian Diabetes Association (Diabetesforbundet) for their engagement in this study. This study is funded by the Northern Norway Regional Health Authority (Helse Nord RHF), grant number HNF1370-17.

\section{References}

[1] Norwegian Ministry of Health and Care Services. NCD Strategy 2013-2017 For the prevention, diagnosis, treatment and rehabilitation of four noncommunicable diseases: cardiovascular disease, diabetes, COPD and cancer. Available at: https://goo.gl/bXEAsX

[2] Colberg SR, Sigal RJ, Yardley JE, Riddell MC, Dunstan DW, Dempsey PC, Horton ES, Castorino K, Tate DF. Physical Activity/Exercise and Diabetes: A Position Statement of the American Diabetes Association. Diabetes Care. 2016 Nov;39(11):2065-2079.

[3] Gabarron E, Årsand E, Wynn R. Social Media Use in Interventions for Diabetes: Rapid Evidence-Based Review. J Med Internet Res 2018 Aug 10;20(8):e10303.

[4] Stellefson M, Paige S, Apperson A, Spratt S. Social Media Content Analysis of Public Diabetes Facebook Groups. J Diabetes Sci Technol. 2019 May;13(3):428-438.

[5] Årsand E, Bradway M, Gabarron E. What Are Diabetes Patients Versus Health Care Personnel Discussing on Social Media? J Diabetes Sci Technol 2019 Jan 13;13(2):198-205.

[6] Song Y, Nam S, Park S, Shin IS, Ku BJ. The Impact of Social Support on Self-care of Patients With Diabetes: What Is the Effect of Diabetes Type? Systematic Review and Meta-analysis. Diabetes Educ. 2017 Aug;43(4):396-412.

[7] Vambheim SM, Wangberg SC, Johnsen JA, Wynn R. Language use in an internet support group for smoking cessation: development of sense of community. Inform Health Soc Care 2013;38(1):67-78.

[8] Johnsen JA, Vambheim SM, Wynn R, Wangberg SC. Language of motivation and emotion in an internet support group for smoking cessation: explorative use of automated content analysis to measure regulatory focus. Psychol Res Behav Manag 2014;7:19-29.

[9] Morowatisharifabad MA, Abdolkarimi M, Asadpour M, Fathollahi MS, Balaee P. Study On Social Support for Exercise And Its Impact on the Level of Physical Activity of Patients with Type 2 Diabetes. Open Access Maced J Med Sci. 2019 Jan 4;7(1):143-147.

[10]Cutrona CE. Suhr JA. Controllability of stressful events and satisfaction with spouse support behaviors. Communication Research. 1992;19:154-174.

[11]Coulson NS. Receiving social support online: an analysis of a computer-mediated support group for individuals living with irritable bowel syndrome. Cyberpsychol Behav 2005;8(6):580-4.

[12]Coulson NS, Buchanan H, Aubeeluck A. Social support in cyberspace: a content analysis of communication within a Huntington's disease online support group. Patient Educ Couns 2007;68(2):1738.

[13]Phoenix KHM, Coulson NS. Exploring the communication of social support within virtual communitites: a content analysis of messages posted to an online HIV/AIDS support group. Cyberpsychol Behav 2008;11(3):371-4.

[14]Turner-McGrievy GM, Tate DF. Weight loss social support in 140 characters or less: use of an online social network in a remotely delivered weight loss intervention. Transl Behav Med 2013;3(3):287-94.

[15]Gabarron E, Larbi D, Dorronzoro E, et al. Factors Engaging Users of Diabetes Social Media Channels on Facebook, Twitter, and Instagram: Observational Study. J Med Internet Res 2020;22(9):e21204.

[16]European Centre for Disease Prevention and Control. Social media strategy development-A guide to using social media for public health communication. Stockholm: ECDC; 2016. Available at: https://www.ecdc.europa.eu/sites/default/files/media/en/publications/Publications/social-media-strategyguide-for-public-health-communication.pdf 